\title{
molecules
}

ISSN 1420-3049

www.mdpi.com/journal/molecules

Article

\section{Two New Cholic Acid Derivatives from the Marine Ascidian-Associated Bacterium Hasllibacter halocynthiae}

\section{Sung Hun Kim ${ }^{1,2}$, Yun Kyung Shin ${ }^{3}$, Young Chang Sohn ${ }^{2}$ and Hak Cheol Kwon ${ }^{1, *}$}

1 Natural Medicine Center, Korea Institute of Science and Technology (KIST), Gangneung 210-340, Korea; E-Mail: marineamigo@hotmail.com

2 Division of Applied Marine Biotechnology and Engineering, Faculty of Marine Bioscience and Technology, Gangneung-Wonju National University, Gangneung 210-702, Korea;

E-Mail: ykshin@nfrdi.go.kr

3 Aquaculture Management Division, National Fisheries Research and Development Institute, Busan 619-705, Korea; E-Mail: ykshin@nfrdi.go.kr

* Author to whom correspondence should be addressed; E-Mail: hkwon@kist.re.kr; Tel.: +82-33-650-3504; Fax: +82-33-650-3529.

Received: 13 August 2012; in revised form: 8 October 2012 / Accepted: 17 October 2012 / Published: 22 October 2012

\begin{abstract}
The investigation of secondary metabolites in liquid cultures of a recently discovered marine bacterium, Hasllibacter halocynthiae strain $\mathrm{KME} 002^{\mathrm{T}}$, led to the isolation of two new cholic acid derivatives. The structures of these compounds were determined to be 3,3,12-trihydroxy-7-ketocholanic acid (1) and 3,3,12-trihydroxy-7deoxycholanic acid (2) through HRFABMS and NMR data analyses.
\end{abstract}

Keywords: Hasllibacter halocynthiae; cholic acids; cholanic acid ketal; marine ascidian

\section{Introduction}

Ascidians are marine invertebrates in the phylum Chordata. Among these abundant group members, Halocynthia roretzi is an edible ascidian with rock and artificial structures in shallow ocean waters as its habitats. Ascidians efficiently take up food particles and microorganisms by filter feeding seawater through a pair of siphons. This filter-feeding ability could make ascidians as an ideal source for the discovery of unique marine microorganisms. Although several bacteria associated with Halocynthia roretzi 
have been reported [1-7], the chemical-ecological interactions between the ascidian hosts and their associated bacteria is unclear.

In our previous study, the bacterial strain $\mathrm{KME} 002^{\mathrm{T}}$, isolated from the marine ascidian $(H$. roretzi) was identified as a novel species, Hasllibacter halocynthiae. This belongs to the Roseobacter clade. The members of this clade, which are ubiquitous in various marine habitats, produce a variety of bioactive compounds [8-11]. Three bile acid derivatives: 3,12-dihydroxy-7-ketocholanic acid, 12-hydroxy-3-ketoglycocholanic acid and nutriacholic acid, were identified as major secondary metabolites produced by Hasllibacter halocynthiae [5]. Bile acids are not only physiologically important agents for the digestion of dietary fats, carotenoids and vitamins [12], but also important therapeutic agents for treating cholestasis, gallstone, fatty liver, cardiovascular disease, obesity and diabetes in humans [13]. Bile acids are generally produced in eukaryotic cells and less than 15 bacterial strains are known to produce these metabolites [14-17].

In our further investigations, unique bile acid derivatives produced by strain KME $002^{\mathrm{T}}$ were observed. Two novel cholic acid derivatives, 3,3,12-trihydroxy-7-ketocholanic acid (1) and 3,3,12-trihydroxy-7-deoxycholanic acid (2), were isolated and identified from organic extracts of H. halocynthiae KME $002^{\mathrm{T}}$. The structures of these compounds were determined by 2D-NMR and HRFABMS (high-resolution fast atom bombardment mass spectrometry). This paper describes the isolation and structural elucidation of these two novel cholic acid derivatives, compounds $\mathbf{1}$ and 2 (Figure 1).

Figure 1. Structures of compounds 1 and 2.

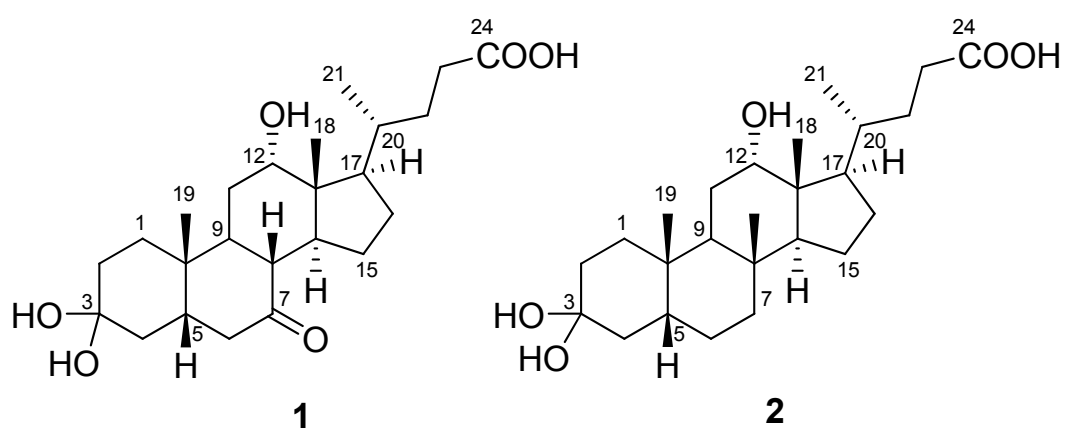

\section{Results and Discussion}

The sequence analysis of the $16 \mathrm{~S}$ rRNA gene placed strain $\mathrm{KME} 002^{\mathrm{T}}$ within the Roseobacter clade in Alphaproteobacteria, and the $16 \mathrm{~S}$ rRNA gene sequence of strain KME $002^{\mathrm{T}}$ showed similarities of 95.0, 94.7 and 94.5\% to Dinoroseobacter shibae, Roseovarius crassostreae and Pseudoruegeria aquimaris, respectively. In addition, comprehensive analyses showed that KME $002^{\mathrm{T}}$ had distinct phenotypic characteristics compared with its close phylogenetic relatives, suggesting a novel genus and species of the family Rhodobacteraceae, which was named Hasllibacter halocynthiae. Cultures of KME $002^{\mathrm{T}}$ were deposited at the Japan Collection of Microorganisms (JCM 16214 ${ }^{\mathrm{T}}$ ) and the Korean Culture Center of Microorganisms (KCCM 90082 ${ }^{\mathrm{T}}$ ).

Strain KME $002^{\mathrm{T}}$ was isolated from the siphon tissue of a marine ascidian, Halocynthia roretzi. To investigate secondary metabolite production by $\mathrm{KME} 002^{\mathrm{T}}$, the strain was cultured in 32 one liter Erlenmeyer flasks, each containing $500 \mathrm{~mL}$ of $\mathrm{A} 1+\mathrm{C}$ liquid medium (total $12 \mathrm{~L}$ ) [10 g of starch 
(Difco), $2 \mathrm{~g}$ of yeast extract (Difco), $1 \mathrm{~g}$ of calcium carbonate (Aldrich, 98\%) and $4 \mathrm{~g}$ of peptone (Difco) in $1 \mathrm{~L}$ sterilized distilled water]. Secondary metabolite production in the culture broth was monitored daily by HPLC analysis using an Agilent 1200 series LC system coupled with an Agilent 6120 Quadrupole mass spectrometer using a Phenomenex Luna C18(2) column $(150 \times 4.60 \mathrm{~mm}$, $5 \mu \mathrm{m}$ ) eluted with a gradient of $10 \%-100 \%$ acetonitrile in water containing $0.05 \%$ formic acid for $30 \mathrm{~min}$ at a flow rate of $0.7 \mathrm{~mL} / \mathrm{min}$. Two major peaks were observed with retention times of 18.3 and $23.5 \mathrm{~min}$ on the fifth day of culture. At the end of the culture period ( 7 days), the culture broth of strain KME $002^{\mathrm{T}}$ was extracted twice with ethyl acetate (EtOAc). The crude EtOAc extract was subjected to an initial separation using reverse-phase flash column chromatography, and the $60 \%$ and $80 \%$ aqueous acetonitrile fractions were purified with preparative HPLC $(\mathrm{C} 18$ column, $10 \times 250 \mathrm{~mm})$ to yield compounds $\mathbf{1}$ and $\mathbf{2}$.

Compound 1 was isolated as a colorless oil. Its molecular formula was deduced as $\mathrm{C}_{24} \mathrm{H}_{38} \mathrm{O}_{6}$ based on HRFABMS (obsd., [M- $\left.\mathrm{H}_{2} \mathrm{O}+\mathrm{Na}\right]^{+}$at $\mathrm{m} / z$ 427.2451) and ${ }^{13} \mathrm{C}-\mathrm{NMR}$ data. The IR spectrum of $\mathbf{1}$ displayed absorption bands at 3,479 and $1,714 \mathrm{~cm}^{-1}$, indicating the presence of hydroxyl and carbonyl functionalities. The ${ }^{1} \mathrm{H}$ - and ${ }^{13} \mathrm{C}-\mathrm{NMR}$ data of $\mathbf{1}$ (Table 1) were almost identical to those of $3 \alpha, 12 \alpha$ dihydroxy-7-ketocholanic acid isolated from the culture broth of a sponge-associated Psychrobacter sp. [17]. However, there was no H-3 carbinol proton signal in the ${ }^{1} \mathrm{H}-\mathrm{NMR}$ spectrum of $\mathbf{1}$, and the C-3 carbon signal was observed much further downfield at $101.7 \mathrm{ppm}$ in the ${ }^{13} \mathrm{C}-\mathrm{NMR}$ spectrum of $\mathbf{1}$. The C-3 quaternary carbon signal showed $\mathrm{HMBC}$ correlation with $\mathrm{H}_{2}-2$ and $\mathrm{H}_{2}-4$, indicating that a dihydroxyl group was attached at the C-3 position (Figure 2). The optical rotation value of $1(+19.0 c$ $0.1, \mathrm{EtOH})$ was similar to that of compound 2 and $12 \alpha$-hydroxy-7-deoxy-3-ketocholanic acid $(+44.1 c$ 1.6, chloroform) [18], indicating that the absolute configurations of the chiral centers in $\mathbf{1}$ are identical to those of these two compounds. Thus, the structure of 1 was assigned as 3,3,12-trihydroxy-7ketocholanic acid.

Compound 2 was obtained as colorless oil that was determined to be $\mathrm{C}_{24} \mathrm{H}_{40} \mathrm{O}_{5}$ based on HRFABMS ([M- $\left.\mathrm{H}_{2} \mathrm{O}+\mathrm{Na}\right]^{+}$at $m / z$ 413.2662) and NMR data (Table 1). The IR spectrum of 2 showed absorption bands almost identical to those of $\mathbf{1}$. The ${ }^{1} \mathrm{H}$ - and ${ }^{13} \mathrm{C}-\mathrm{NMR}$ spectra of compound 2 were similar to those of 3,12-dihydroxy-7-deoxycholanic acid [19], the major differences being the absence of an H-3 carbinol proton signal in the ${ }^{1} \mathrm{H}-\mathrm{NMR}$ spectrum of $\mathbf{2}$ and the downfield shift of the C-3 signal to $102.5 \mathrm{ppm}$ in the ${ }^{13} \mathrm{C}$-NMR spectrum of $\mathbf{2}$, as observed in $\mathbf{1}$. The quaternary carbon signal at $102.5 \mathrm{ppm}$ showed $\mathrm{HMBC}$ correlations with $\mathrm{H}_{2}-2$ and $\mathrm{H}_{2}-4$, indicating that a dihydroxyl group was attached to the C-3 carbon, again similar to the structure of $\mathbf{1}$. In addition, the optical rotation values of 2 and 12 $\alpha$-hydroxy-7-deoxy-3-ketocholanic acid [18] were +25.0 (c 0.1, EtOH) and +44.1 (c 1.6, chloroform), respectively. These data indicated that the structure of $\mathbf{2}$ has the same absolute configuration as 3-dimethoxy-12-hydroxycholanic acid and 12 $\alpha$-hydroxy-7-deoxy-3-ketocholanic acid. Thus, the structure of $\mathbf{2}$ was determined to be 3,3,12-trihydroxy-7-deoxycholanic acid. 
Table 1. ${ }^{1} \mathrm{H}$ and ${ }^{13} \mathrm{C}$-NMR spectral data for compounds $\mathbf{1}$ and $\mathbf{2}$ in methanol- $d_{4}$.

\begin{tabular}{|c|c|c|c|c|c|c|}
\hline \multirow{3}{*}{$\begin{array}{c}\text { Position } \\
1\end{array}$} & \multicolumn{3}{|l|}{1} & \multicolumn{3}{|l|}{2} \\
\hline & \multirow{2}{*}{$\begin{array}{c}\boldsymbol{\delta}_{\mathbf{H}} \text { mult }(\boldsymbol{J}, \mathbf{H z})^{a} \\
1.67 \mathrm{~m}, 1.33 \mathrm{~m}\end{array}$} & \multicolumn{2}{|c|}{$\delta_{\mathrm{C}}{ }^{b}$} & \multirow{2}{*}{$\begin{array}{c}\boldsymbol{\delta}_{\mathrm{H}} \text { mult }(\boldsymbol{J}, \mathbf{H z})^{a} \\
1.62 \mathrm{~m}, 1.15 \mathrm{~m}\end{array}$} & \multicolumn{2}{|c|}{$\delta_{\mathrm{C}}^{b}$} \\
\hline & & 33.2 & $\mathrm{CH}_{2}$ & & 34.2 & $\mathrm{CH}_{2}$ \\
\hline 2 & $1.75 \mathrm{~m}, 1.38 \mathrm{~m}$ & 28.0 & $\mathrm{CH}_{2}$ & $1.88 \mathrm{~m}, 1.25 \mathrm{~m}$ & 28.1 & $\mathrm{CH}_{2}$ \\
\hline 3 & & 101.7 & $\mathrm{C}$ & & 102.5 & $\mathrm{C}$ \\
\hline 4 & $1.72 \mathrm{~m}, 1.26 \mathrm{~m}$ & 35.8 & $\mathrm{CH}_{2}$ & $1.83,1.57 \mathrm{~m}$ & 34.6 & $\mathrm{CH}_{2}$ \\
\hline 5 & $2.02 \mathrm{~m}$ & 45.9 & $\mathrm{CH}$ & $1.50 \mathrm{~m}$ & 41.3 & $\mathrm{CH}$ \\
\hline 6 & $2.97 \mathrm{dd}(12.5,6.0), 1.84 \mathrm{~m}$ & 46.1 & $\mathrm{CH}_{2}$ & $1.72 \mathrm{~m}, 1.48 \mathrm{~m}$ & 28.4 & $\mathrm{CH}_{2}$ \\
\hline 7 & & 215.1 & $\mathrm{C}$ & $1.86 \mathrm{~m}, 1.29 \mathrm{~m}$ & 28.8 & $\mathrm{CH}_{2}$ \\
\hline 8 & $2.56 \mathrm{dd}(11.5,11.5)$ & 50.9 & $\mathrm{CH}$ & $1.47 \mathrm{~m}$ & 37.4 & $\mathrm{CH}$ \\
\hline 9 & $2.23 \mathrm{~m}$ & 37.4 & $\mathrm{CH}$ & $1.87 \mathrm{~m}$ & 34.4 & $\mathrm{CH}$ \\
\hline 10 & & 36.2 & $\mathrm{C}$ & & 35.6 & $\mathrm{C}$ \\
\hline 11 & $1.77 \mathrm{~m}, 1.54 \mathrm{~m}$ & 30.9 & $\mathrm{CH}_{2}$ & $1.53 \mathrm{~m}$ & 30.2 & $\mathrm{CH}_{2}$ \\
\hline 12 & 3.98 br t (3.0) & 73.0 & $\mathrm{CH}$ & 3.96 br t (3.0) & 74.2 & $\mathrm{CH}$ \\
\hline 13 & & 47.7 & $\mathrm{C}$ & & 47.7 & $\mathrm{C}$ \\
\hline 14 & $1.98 \mathrm{~m}$ & 42.1 & $\mathrm{CH}$ & $1.60 \mathrm{~m}$ & 49.5 & $\mathrm{CH}$ \\
\hline 15 & $2.15 \mathrm{~m}, 1.01 \mathrm{~m}$ & 25.5 & $\mathrm{CH}_{2}$ & $1.62 \mathrm{~m}, 1.10 \mathrm{~m}$ & 25.0 & $\mathrm{CH}_{2}$ \\
\hline 16 & $1.90 \mathrm{~m}, 1.29 \mathrm{~m}$ & 28.9 & $\mathrm{CH}_{2}$ & $1.44 \mathrm{~m}, 1.13 \mathrm{~m}$ & 27.5 & $\mathrm{CH}_{2}$ \\
\hline 17 & $1.80 \mathrm{~m}$ & 47.3 & $\mathrm{CH}$ & $1.84 \mathrm{~m}$ & 48.3 & $\mathrm{CH}$ \\
\hline 18 & $0.72 \mathrm{~s}$ & 13.4 & $\mathrm{CH}_{3}$ & $0.71 \mathrm{~s}$ & 13.3 & $\mathrm{CH}_{3}$ \\
\hline 19 & $1.23 \mathrm{~s}$ & 23.4 & $\mathrm{CH}_{3}$ & $0.94 \mathrm{~s}$ & 23.8 & $\mathrm{CH}_{3}$ \\
\hline 20 & $1.41 \mathrm{~m}$ & 36.7 & $\mathrm{CH}$ & $1.43 \mathrm{~m}$ & 36.9 & $\mathrm{CH}$ \\
\hline 21 & $1.01 \mathrm{~d}(6.5)$ & 17.8 & $\mathrm{CH}_{3}$ & $1.01 \mathrm{~d}(6.5)$ & 17.7 & $\mathrm{CH}_{3}$ \\
\hline 22 & $1.79 \mathrm{~m}, 1.36 \mathrm{~m}$ & 32.4 & $\mathrm{CH}_{2}$ & $1.79 \mathrm{~m}, 1.33 \mathrm{~m}$ & 32.5 & $\mathrm{CH}_{2}$ \\
\hline \multirow[t]{2}{*}{23} & 2.35 ddd $(15.0,9.5,5.0)$ & 32.0 & $\mathrm{CH}_{2}$ & $2.35 \operatorname{ddd}(15.5,10.0,5.5)$ & 32.2 & $\mathrm{CH}_{2}$ \\
\hline & $2.26 \mathrm{~m}$ & & & 2.22 ddd $(7.0,9.5,16.0)$ & & \\
\hline 24 & & 176.6 & $\mathrm{C}$ & & 178.3 & $\mathrm{C}$ \\
\hline
\end{tabular}

${ }^{a} 500 \mathrm{MHz} ;{ }^{b} 125 \mathrm{MHz}$; Reference chemical shifts: $\delta_{\mathrm{H}} 3.31, \delta_{\mathrm{C}} 49.0$ for methanol- $d_{4}$.

Figure 2. Key HMBC correlations of compound 1.

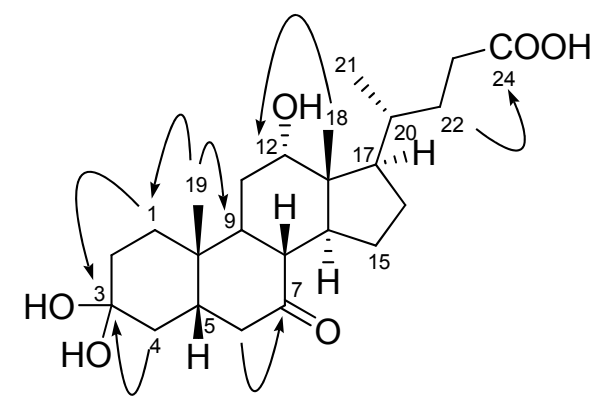

Compounds 1 and $\mathbf{2}$ may be produced by microbial transformation of cholic acid or deoxycholic acid in the liquid medium (Figure 3). Actually, cholic acid is often found in Bacto peptone which is an ingredient of the $\mathrm{A} 1+\mathrm{C}$ liquid medium [20]. However, the isolation of $\mathbf{1}$ and $\mathbf{2}$ is considered to contribute to a better understanding of the chemical diversity of steroidal structures because the 3,3-dihydroxylated steroid derivative is very rare in Nature. 
Figure 3. LC/MS chromatograms: (A) A1+C liquid medium, (B) Bacto peptone (Difco 211677) solution, (C) Cholic acid (Sigma C1129), (D) Deoxycholic acid (Sigma D2510), (E) Culture extract of strain KME $002^{\mathrm{T}}$ (Day 7), (F) Compound 1, (G) Compound 2.

\section{(A)}

(B)

(C)

(D)

(E)

(F)

(G)

\section{Experimental Procedures}

\subsection{General}

Optical rotation was measured with a Perkin-Elmer model 343 polarimeter (Perkin-Elmer, Waltham, MA, USA). FT-IR spectra were acquired with a Nicolet iS10 spectrometer (Thermo Fisher Scientific, Waltham, MA, USA). ${ }^{1} \mathrm{H}-,{ }^{13} \mathrm{C}-\mathrm{NMR}$ and 2D NMR (gHSQC, gHMBC and gCOSY) data were obtained in $\mathrm{CD}_{3} \mathrm{OD}\left(\delta_{\mathrm{H}} 3.31\right.$ and $\left.\delta_{\mathrm{C}} 49.0\right)$ on a Varian Unity Plus $500 \mathrm{MHz}$ NMR System (Varian, Palo Alto, CA, USA). Low-resolution mass spectra were recorded with an Agilent 1200 series LC system coupled with an Agilent 6120 Quadrupole mass spectrometer (Agilent Technologies, Santa Clara, CA, USA). HRFABMS data were obtained on a JEOL/JMS-AX505WA instrument at the National Center for Inter-University Research Facilities of Seoul National University. Cosmosil 75 C18-Prep (Nacalai Tesque, Kyoto, Japan) was used for reverse-phase flash column chromatography. Preparative HPLC separations were performed using a Gilson 321 HPLC system (Gilson, Middleton, WI, USA) equipped with a Phenomenex Luna C18(2) column $(250 \times 10.00 \mathrm{~mm}, 10 \mu \mathrm{m})$ and a differential refractive index detector (Shodex, RI-101). A YL9100 HPLC system (Younglin, Korea) equipped with a Phenomenex Luna C18(2) column $(150 \times 4.60 \mathrm{~mm}, 5 \mu \mathrm{m})$ and an ELSD ZAM 3000 detector (Schambeck SFD GmbH, Bad Honnef, Germany) was used for HPLC analysis. 


\subsection{Collection, Isolation and Identification of Strain KME $002^{T}$}

Hasllibacter halocynthiae sp. KME $002^{\mathrm{T}}$ was isolated from a marine ascidian, Halocynthia roretzi, collected at a depth of $15 \mathrm{~m}$ (water temperature: $17^{\circ} \mathrm{C}$ ) near Kyung-Po beach in Korea (June 2007). The ascidian was collected and immediately washed with autoclaved seawater, and its atrial and branchial siphons were finely ground and diluted with filtered, autoclaved seawater at a ratio of 1:10. The diluted suspension $(100 \mu \mathrm{L})$ was spread on an $\mathrm{A} 1+\mathrm{C}$ agar plate. The $\mathrm{A} 1+\mathrm{C}$ agar medium consists of $10 \mathrm{~g}$ starch (Difco Laboratories, Detroit, MI, USA), $4 \mathrm{~g}$ peptone (Difco), $2 \mathrm{~g}$ yeast extract (Difco), $1 \mathrm{~g}$ calcium carbonate (Aldrich, 98\%) and $18 \mathrm{~g}$ agar (Difco) in 1 liter of filtered seawater. The plate was incubated for 3 weeks at $25{ }^{\circ} \mathrm{C}$ under aerobic conditions. KME $002^{\mathrm{T}}$ was isolated as circular, convex and light red colonies on an $\mathrm{A} 1+\mathrm{C}$ agar plate. The isolate was stored at $-80{ }^{\circ} \mathrm{C}$ in $\mathrm{A} 1+\mathrm{C}$ liquid medium supplemented with $20 \%$ glycerol (v/v). KME $002^{\mathrm{T}}$ was identified using a polyphasic approach, including phenotypic, chemotaxonomic and genetic analyses [5]. Based on these polyphasic characteristics, strain KME $002^{\mathrm{T}}$ was designated Hasllibacter halocynthiae, a novel genus and species

of the family Rhodobacteraceae. KME $002^{\mathrm{T}}$ was deposited at the Japan Collection of Microorganisms $\left(=\mathrm{JCM} 16214^{\mathrm{T}}\right)$ and the Korean Culture Center of Microorganisms (=KCCM $\left.90082^{\mathrm{T}}\right)$.

\subsection{Cultivation and Extraction}

KME $002^{\mathrm{T}}$ was cultured aerobically in $\mathrm{A} 1+\mathrm{C}$ liquid medium $(25 \mathrm{~mL})$ with shaking at $200 \mathrm{rpm}$ for 4 days at $25{ }^{\circ} \mathrm{C}$, and the seed culture was then transferred to $1 \mathrm{~L}$ Erlenmeyer flasks containing $500 \mathrm{~mL}$ of $\mathrm{A} 1+\mathrm{C}$ liquid medium (total $12 \mathrm{~L}$ ). The culture flasks were incubated aerobically with shaking at $200 \mathrm{rpm}$ for 7 days at $25^{\circ} \mathrm{C}$. Secondary metabolites in the culture broth were analyzed daily from day 3 to 7 using an Agilent 1200 series LC/MS system equipped with a Phenomenex Luna C18(2) column $(150 \times 4.60 \mathrm{~mm}, 5 \mu \mathrm{m})$ and eluted with a linear aqueous acetonitrile gradient from 10 to $100 \%$ in $0.05 \%$ formic acid at a flow rate of $0.7 \mathrm{~mL} / \mathrm{min}$. The culture broth (day 7 ) of strain $\mathrm{KME} 002^{\mathrm{T}}$ was extracted twice with ethyl acetate $(1: 1, \mathrm{v} / \mathrm{v})$. The ethyl acetate solutions were then decanted, filtered and concentrated under reduced pressure to yield $650 \mathrm{mg}$ of crude extracts.

\subsection{Separation and Purification of Two New Bile Acid Derivatives, Compounds $\mathbf{1}$ and $\mathbf{2}$}

The culture extracts from strain $\mathrm{KME} 002^{\mathrm{T}}$ were initially separated using $\mathrm{C} 18$ flash column chromatography by step gradient elution with acetonitrile/water (20:80, 40:60, 60:40, 80:20 and 100:0) to produce five fractions (fractions I-V). Fraction III (79.0 mg) was dried in vacuo and fractionated by preparative HPLC using an isocratic elution of $45 \%$ acetonitrile in water containing $0.02 \%$ trifluoroacetic acid for $30 \mathrm{~min}$ (flow rate $4 \mathrm{~mL} / \mathrm{min}$, Phenomenex Luna C18(2), $10 \times 250 \mathrm{~mm}, 10 \mu \mathrm{m}$ ) to yield four subfractions (fractions III-1 to III-4). Compound 1 ( $7.9 \mathrm{mg}, t_{\mathrm{R}} 23.5 \mathrm{~min}$ ) was purified from subfraction III-2 (10.5 mg) by preparative HPLC using isocratic elution with $35 \%$ acetonitrile in water containing $0.02 \%$ trifluoroacetic acid for $30 \mathrm{~min}$ (flow rate $4 \mathrm{~mL} / \mathrm{min}$, Phenomenex Luna C18(2), $10 \times 250 \mathrm{~mm}$, $10 \mu \mathrm{m})$. Fraction IV (36.9 $\mathrm{mg})$ was dried in vacuo and fractionated by preparative HPLC using isocratic elution with $50 \%$ acetonitrile in water containing $0.02 \%$ trifluoroacetic acid for $1 \mathrm{~h}$ (flow rate $4 \mathrm{~mL} / \mathrm{min}$, Phenomenex Luna C18(2), $10 \times 250 \mathrm{~mm}, 10 \mu \mathrm{m}$ ) to yield four subfractions (fractions IV-1 to IV-4). Compound 2 (3.2 $\left.\mathrm{mg}, t_{\mathrm{R}} 13.0 \mathrm{~min}\right)$ was purified from subfraction IV-4 (4.8 $\mathrm{mg}$ ) by preparative 
HPLC using isocratic elution with $60 \%$ acetonitrile in water containing $0.02 \%$ trifluoroacetic acid for $30 \mathrm{~min}$ (flow rate $4 \mathrm{~mL} / \mathrm{min}$, Phenomenex Luna C18(2), $10 \times 250 \mathrm{~mm}, 10 \mu \mathrm{m}$ ).

3,3,12-Trihydroxy-7-ketocholanic acid (1): colorless oil; $[\alpha]_{D}^{25}:+19.0$ (c 0.10, EtOH); IR (film) $v_{\max }$ 3479, 3056, 2952, 1714, $736 \mathrm{~cm}^{-1}$; ${ }^{1} \mathrm{H}$ - and ${ }^{13} \mathrm{C}-\mathrm{NMR}$ spectra: see Table 1; HRFABMS $\left[\mathrm{M}-\mathrm{H}_{2} \mathrm{O}+\mathrm{Na}\right]^{+}$ $m / z 427.2451$ (calcd. for $\mathrm{C}_{24} \mathrm{H}_{36} \mathrm{O}_{5} \mathrm{Na}, 427.2460$ ).

3,3,12-Trihydroxy-7-deoxycholanic acid (2): colorless oil; $[\alpha]_{D}^{25}:+25.0$ (c 0.10 , EtOH); IR (film) $v_{\max }$ 3444, 2939, 2868, 1700, 1206, $1140 \mathrm{~cm}^{-1}$; ${ }^{1} \mathrm{H}$ - and ${ }^{13} \mathrm{C}-\mathrm{NMR}$ spectra: see Table 1; HRFABMS $\left[\mathrm{M}-\mathrm{H}_{2} \mathrm{O}+\mathrm{Na}\right]^{+} m / z 413.2662$ (calcd. for $\mathrm{C}_{24} \mathrm{H}_{38} \mathrm{O}_{4} \mathrm{Na}, 413.2668$ ).

\section{Conclusions}

Two new cholic acid ketals were isolated from the new marine-derived bacterium Hasllibacter halocynthiae $\mathrm{KME} 002^{\mathrm{T}}$. The basic structural features of both compounds $\mathbf{1}$ and $\mathbf{2}$, identified by spectroscopic methods, including 2D-NMR experiments, was a 12-hydroxycholanic acid core with a unique 3,3-dihydroxy group. For decades, investigation at the chemical and biochemical levels to better understand the chemical diversity of microbial secondary metabolites has made continuous and impressive progress in the field of natural products. The isolation of $\mathbf{1}$ and $\mathbf{2}$ is expected to contribute to a better understanding of the structural diversity of cholic acid derivatives.

\section{Acknowledgments}

This research was conducted with funds from the National Fisheries Research and Development Institute (RP-2012-AQ-077) and partially supported by the Korea Institute of Science and Technology (KIST) institutional program, grant number 2Z03550, Republic of Korea.

\section{References}

1. Azumi, K.; Yokosawa, H.; Ishii, S. Halocyamines: Novel antimicrobial tetrapeptide-like substances isolated from the hemocytes of the solitary ascidian Halocynthia. roretzi. Biochemistry 1990, 29, 159-165.

2. Tsukamoto, S.; Kato, H.; Hirota, H.; Fusetani, N. Antibacterial and antifungal sulfated alkane and alkenes from the Hepatopancreas of the ascidian Halocynthia. roretzi. J. Nat. Prod. 1994, 57, 1606-1609.

3. Konishi, I.; Hosokawa, M.; Sashima, T.; Kobayashi, H.; Miyashita, K. Halocynthiaxanthin and fucoxanthinol isolated from Halocynthia. roretzi induce apoptosis in human leukemia, breast and colon cancer cells. Comp. Biochem. Physiol. C Toxicol. Pharmacol. 2006, 142, 53-59.

4. Kim, S.H.; Yang, H.O.; Sohn, Y.C.; Kwon, H.C. Aeromicrobium. halocynthiae sp. nov., A taurocholic acid-producing bacterium isolated from the marine ascidian Halocynthia. roretzi. Int. J. Syst. Evol. Microbiol. 2010, 60, 2793-2798.

5. Kim, S.H.; Yang, H.O.; Kwon, H.C. Hasllibacter. halocynthiae gen. nov., sp. nov., A nutriacholic acid-producing bacterium isolated from the marine ascidian Halocynthia. roretzi. Int. J. Syst. Evol. Microbiol. 2012, 62, 624-631. 
6. Kim, Y.-O.; Park, S.Y.; Nam, B.-H.; Kang, S.-J.; Hur, Y.B.; Lee, S.-J.; Oh, T.-K.; Yoon, J.-H. Ruegeria. halocynthiae sp. nov., Isolated from sea squirt Halocynthia. roretzi. Int. J. Syst. Evol. Microbiol. 2012, 62, 925-930.

7. Kim, Y.-O.; Kong, H.J.; Park, S.Y.; Kang, S.-J.; Kim, W.-J.; Kim, K.-K.; Oh, T.-K.; Yoon, J.-H. Roseovarius. halocynthiae sp. nov., Isolated from sea squirt Halocynthia. roretzi. Int. J. Syst. Evol. Microbiol. 2012, 62, 931-936.

8. Brinkhoff, T.; Giebel, H.-A.; Simon, M. Diversity, ecology, and genomics of the Roseobacter. clade: A short overview. Arch. Microbiol. 2008, 189, 531-539.

9. Martens, T.; Gram, L.; Grossart, H.-P.; Kessler, D.; Mueller, R.; Simon, M.; Wenzel, S.C.; Brinkhoff, T. Bacteria of the Roseobacter. clade show potential for secondary metabolite production. Microb. Ecol. 2007, 54, 31-42.

10. Paul, V.J.; Ritson-Williams, R.; Sharp, K. Marine chemical ecology in benthic environments. Nat. Prod. Rep. 2011, 28, 345-387.

11. Gram, L.; Melchiorsen, J.; Bruhn, J.B. Antibacterial activity of marine culturable bacteria collected from a global sampling of ocean surface waters and surface swabs of marine organisms. Mar. Biotechnol. 2010, 12, 439-451.

12. Mukhopadhyay, S.; Maitra, U. Chemistry and biology of bile acids. Curr. Sci. 2004, 87, 1666-1683.

13. Chiang, J.Y.L. Bile Acid Metabolism. In Molecular Pathology of Liver Diseases; Monga, S.P.S., Ed.; Springer: Pittsburgh, PA, USA, 2011; pp. 165-179.

14. Park, S.C.; Kim, C.J.; Uramoto, M.; Yun, H.I.; Yoon, K.H.; Oh, T.K. Antibacterial substance produced by Streptococcus faecium under anaerobic culture. Biosci. Biotechnol. Biochem. 1995, 59, 1966-1967.

15. Maneerat, S.; Nitoda, T.; Kanzaki, H.; Kawai, F. Bile acids are new products of a marine bacterium, Myroides. sp. strain SM1. Appl. Michrobiol. Biotechnol. 2005, 67, 679-683.

16. Kim, D.; Lee, J.S.; Kim, J.; Kang, S.-J.; Yoon, J.-H.; Kim, W.G.; Lee, C.H. Biosynthesis of bile acids in a variety of marine bacterial taxa. J. Microbiol. Biotechnol. 2007, 17, 403-407.

17. Li, H.; Shinde, P.B.; Lee, H.J.; Yoo, E.S.; Lee, C.-O.; Hong, J.; Choi, S.H.; Jung, J.H. Bile acid derivatives from a sponge-associated bacterium Psychrobacter. sp. Arch. Pharm. Res. 2009, 32, 857-862.

18. Bortolini, O.; Fantin, G.; Fogagnolo, M.; Mari, L. Two-way enantioselective control in the epoxidation of alkenes with the keto bile acid-Oxone system. Tetrahedron 2006, 62, 4482-4490.

19. Waterhous, D.V.; Barnes, S.; Muccio, D.D. Nuclear magnetic resonance spectroscopy of bile acids. Development of two-dimensional NMR methods for the elucidation of proton resonance assignments for five common hydroxylated bile acids, and their parent bile acid, $5 / 3$ cholanic acid. J. Lip. M Res. 1985, 26, 1068-1078.

20. Kamekura, M.; Osterhelt, D.; Wallace, R.; Anderson, P.; Kushner, D.J. Lysis of halobacteria in bacto-peptone by bile acids. Appl. Environ. Microbiol. 1988, 54, 990-995.

Sample Availability: Samples of the compounds are available from the authors.

(C) 2012 by the authors; licensee MDPI, Basel, Switzerland. This article is an open access article distributed under the terms and conditions of the Creative Commons Attribution license (http://creativecommons.org/licenses/by/3.0/). 